\title{
Dynamic Modelling of Environment-Industry Systems
}

\author{
Igor Kantardgi \\ Moscow State Civil Engineering University, Dept. of Water Management and Sea Ports, \\ Novokosinskaya Street, 14-1-4, 111672, Moscow, Russia \\ kantardgi@rambler.ru Igor_Kantardgi@stankin.ru
}

\begin{abstract}
The various kinds of modelling of environment-industry systems in environmental management are considered. The system dynamics models of interaction between industrial production and environment are developed. The basic model of the main factors and links is upgraded to the detailed models, which may be applied directly in the management process. The models are applied in the system of various levels, including model of Moscow city and machine-building enterprise. It's shown that the modelling provides the necessary information for the support the decision-making.
\end{abstract}

\section{Introduction}

The modern approach to supply the sustainable development of industry relates to the concept of the environmental management which is presented in the international standards serial ISO 14000 [1, as an example of standard from serial]. The practical application of the environmental management needs the information support. This information may be obtained from the mathematical modelling of various systems.

International standard ISO 14001 is focused specifically onto environmental management. The Life Cycle Assessment methodology [1] gives the inventory panel of the sources of environmental load. To reach the integrated indicator of the environmental load in the terms of environmental damage, the next stages of modelling have to follow the first inventory stage - Fig.1 [2]:

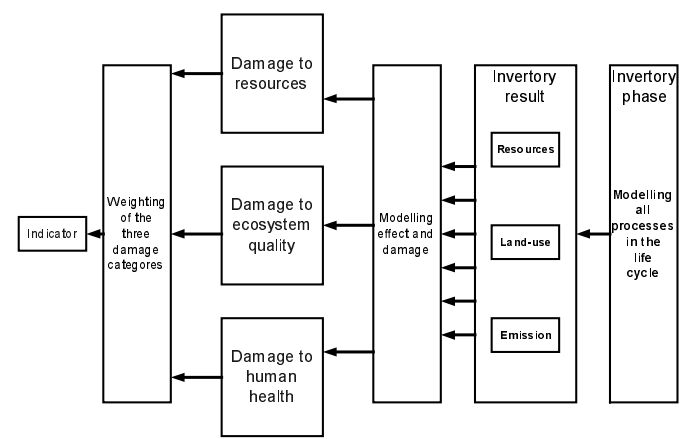

Fig. 1. Main steps of Eco-indicator 99 methodology (from [2]) 
- $\quad$ Fate analysis (links from emissions to concentrations);

- Effect analysis (links from concentrations to health effects, resources and ecosystems changes);

- Damage analysis (from effects to assessment of damages of human health, resources, and ecosystems);

- LC eco-indicator determination through damages normalization and weighting.

Fate, effects, and damage analysis is supported by specific kinds of modelling. But the management procedures need the special system models, what can provide the information for the factual management [3]. These models are developed in the report.

The system dynamics modelling software VENSIM PLE by Ventana Systems Inc. (academic version) [4] is applied for model computer realization.

\section{Basic Model of Environment-Industry Interaction}

The basic model (model 3) was designed to study the main factors and links between them. It's also used for development of the more realistic model versions.

The model is presented in Fig.2. It includes two parts: environmental damage and economy of enterprise. In this model the environmental damage is presented by the total pollution flow directed into environment. The enterprise pays the environmental taxes what are proportional to the difference between real pollutant flow and normative quota of pollution. The coefficient of proportionality is the environmental taxes rate.

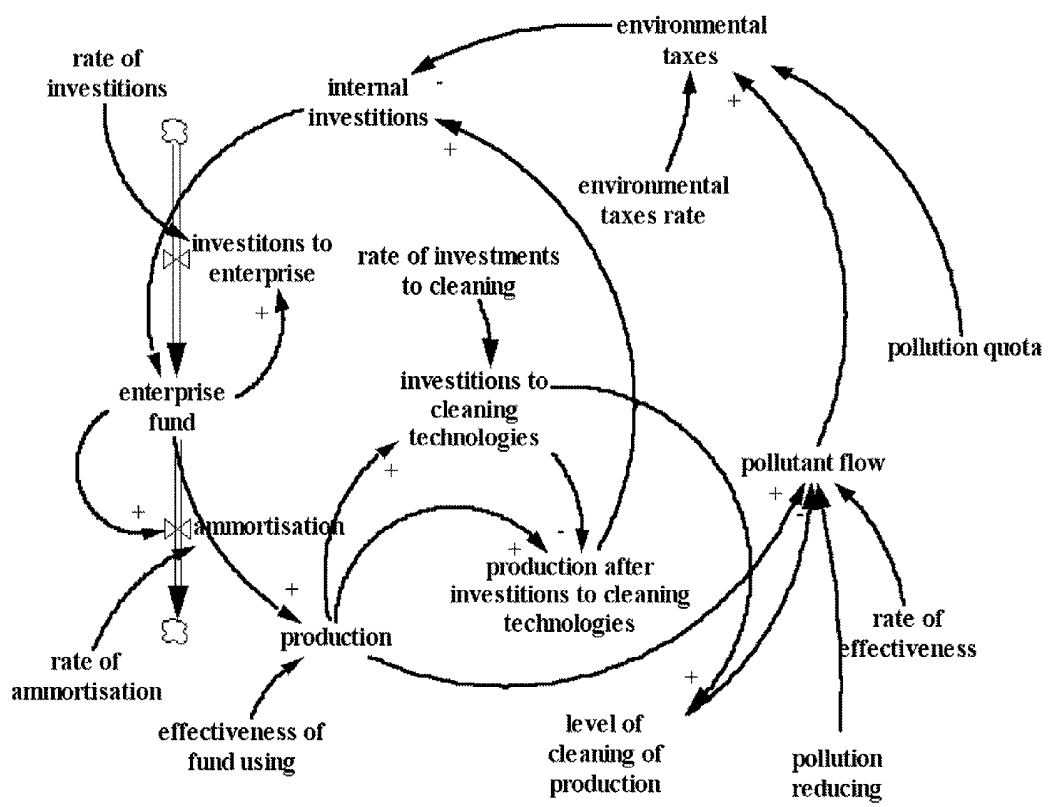

Fig. 2. The basic model simulating environment-industry main links 
The charge of the benefit after paying the environmental taxes may be spent for the internal investments in the production. To decrease the pollution flow and environmental taxes the part of the benefit is directed to the cleaning technologies. So, the major feedback loop of the model is the following one:

Enterprise fund - production - investments in cleaning technologies - level of cleaning production - pollutant flow - environmental taxes - internal investments enterprise fund.

This feedback loop is positive (Fig.2), and to control the system the following negative feedback loop is included:

\section{Production - investments in cleaning technologies - production after investments in \\ cleaning technologies - internal investments - enterprise fund-production .}

The example of simulation with the basic model is shown in Fig.3. The time step of the model is one year, the model period is 6 years, and the simulated enterprise is successful in decreasing of the environmental pollution.

\section{Graph for pollutant flow}

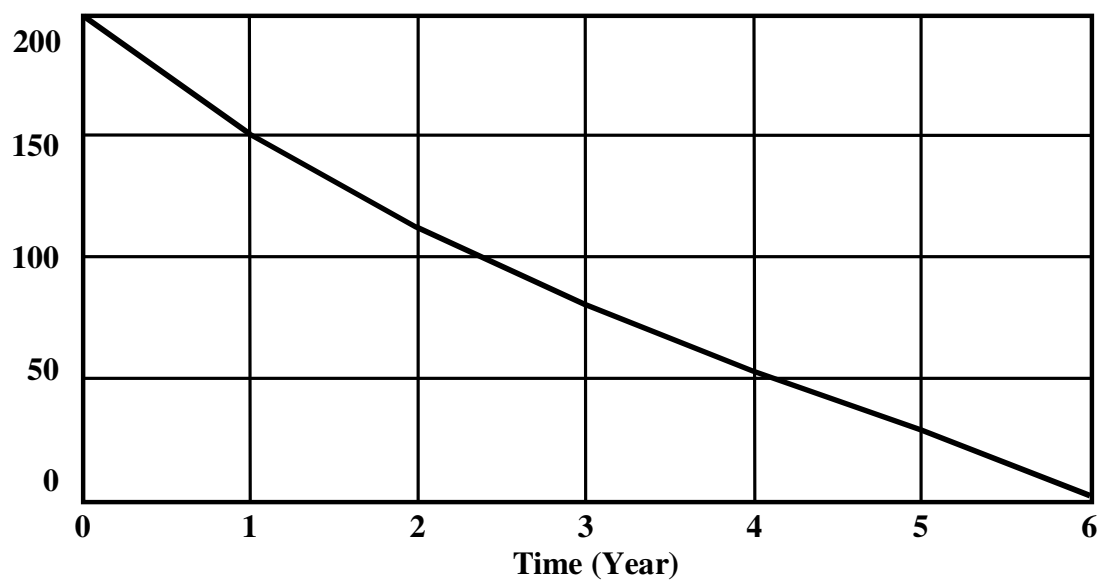

pollutant flow : Current

tons/Year

Fig. 3. Simulation of the total pollutant flow evolution by the basic model

The nontrivial results may be obtained from simulation with the next version of the basic model with more complicated definition of the environmental taxes. The model (model 4) is presented in Fig.4. 


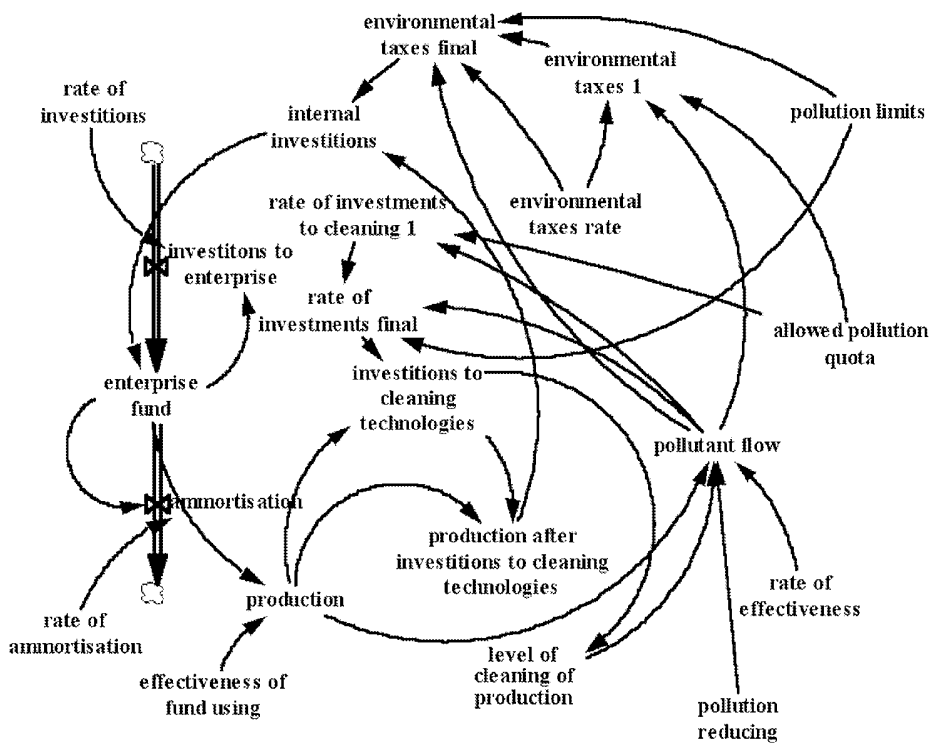

Fig. 4. Model 4 with two-steps limits of pollution

In model 4 the environmental taxes depend on the level of the factual pollutants flow in comparison with the allowed quota or normative limit. If the level of the factual pollutants flow exceeds the normative limit the environmental taxes rate five times more than if not.

Model also utilizes the more complicated strategy of enterprise: the investments in the new technologies increase depending on the results of decrease of pollutant flow in the previous year.

Graph for pollutant flow

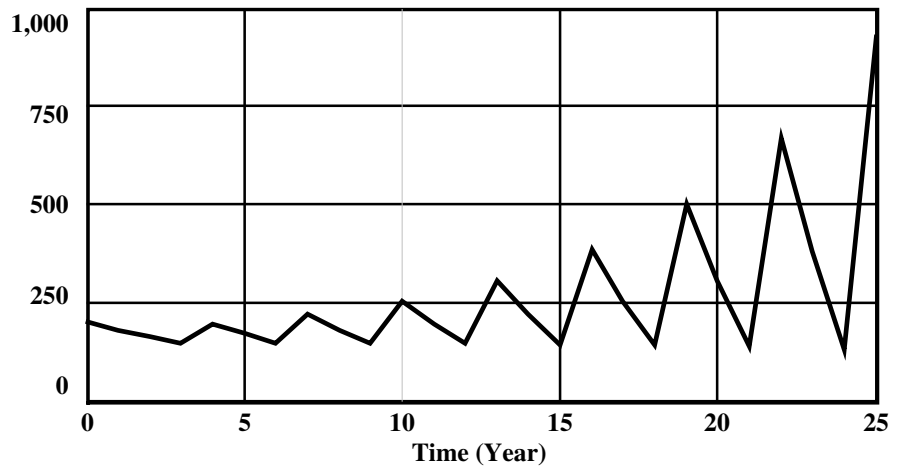

pollutant flow : Current tons/Year

Fig. 5. Simulated oscillations of pollutant flow 
As the simulation result the oscillations of the factors were obtained - fig. 5 . The period of oscillations is 3 years. The explanation of the pollutant flow periodic variations is clear. If in the previous year the pollutant flow is lower than quota, the management of enterprise cut the investments in cleaning technologies in the current year what result in the increase of the pollutant flow in the next year. The amplitude of the oscillations increases with time in relation with the increase of production.

The approach to improve the situation may be found by simulation also. The problem is to find the minimal investments volume in the cleaning technologies in the years with allowed pollutant flows what supports the sustainable development of enterprise.

The found optimum is shown in Fig.6. The simulation has been carried out for the same boundary and initial conditions. The other factors like enterprise fund, production, and environmental taxes show the similar dynamic behavior. The oscillations are obtained in all cases when the initial pollutant flow is close to limit.

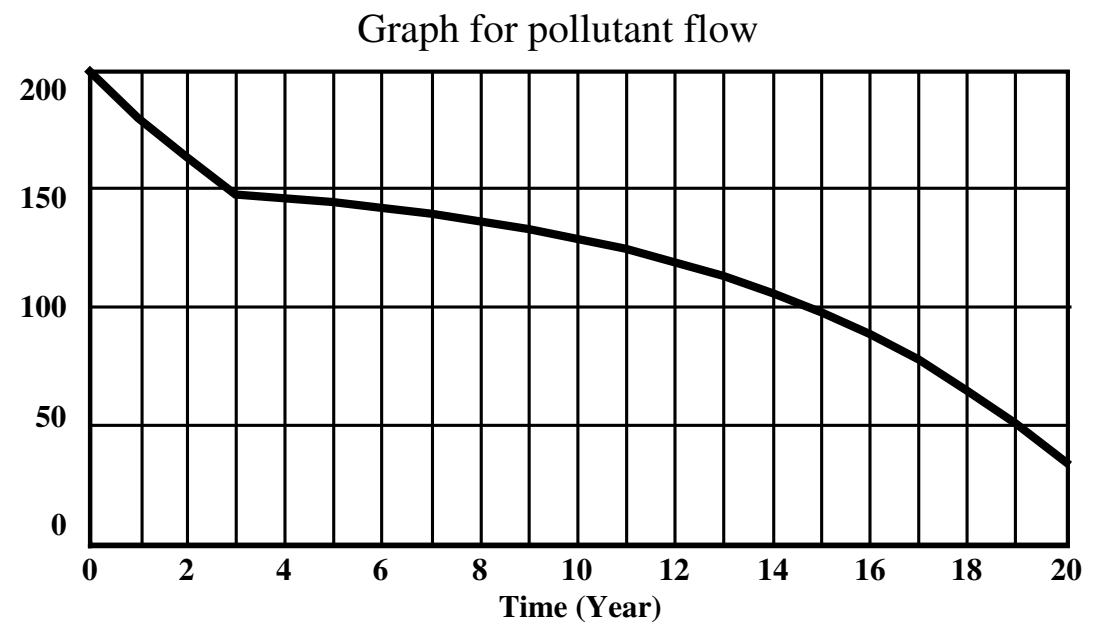

pollutant flow : Current

tons/Year

Fig. 6. Improved environmental management of enterprise (simulation result)

\section{Working Model}

The working model is designed for selected pollutant. The example is shown below for the dangerous Chromium VI compounds emitted into air. The causal loop diagram of the model (model 8) is shown in Fig.7. 


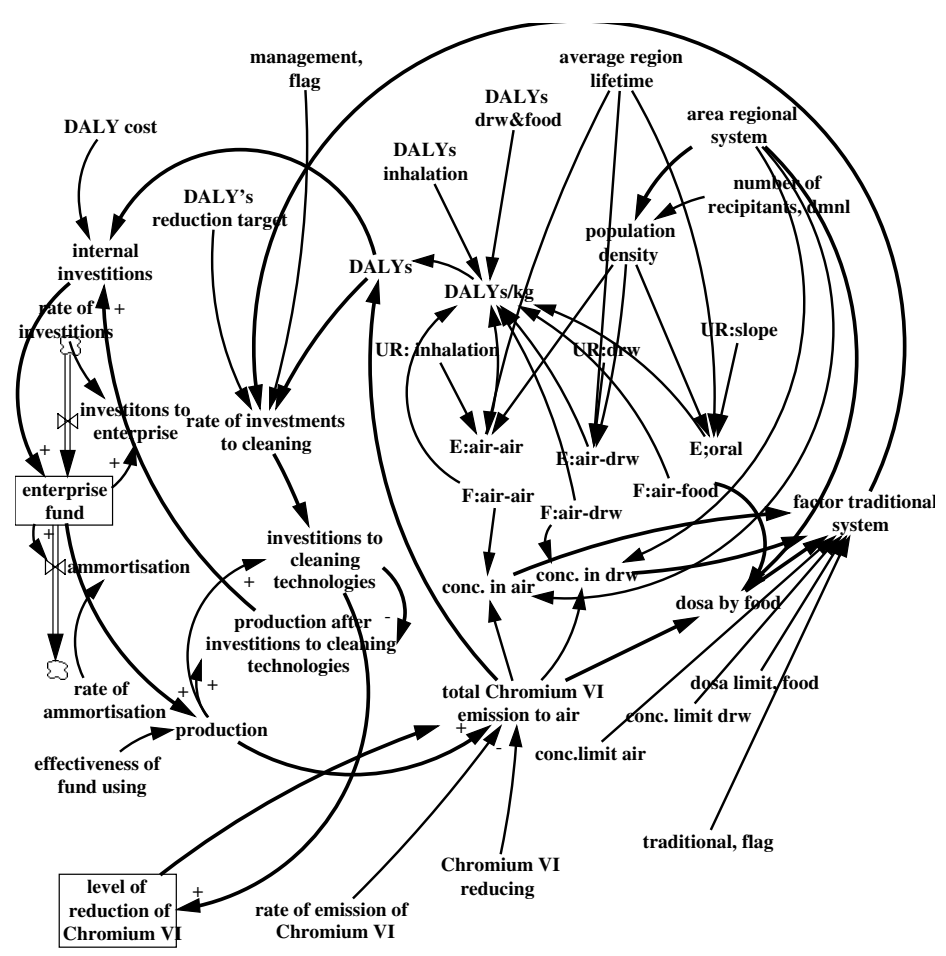

Fig. 7. Model of Chromium VI emission to air environmental damage

The environmental damage to human health is measured in DALYs (Disability Adjusted life Years) scale. The model provides two possibilities of control. The first approach is basing on the simulation the traditional control when factual concentration of the substance is compared with normative limits. The concentration of Ch VI oxides in air, drinking water (drw) and food may be applied. To define the concentrations in water and food the fate factors $(\mathrm{F})$ are used [2].

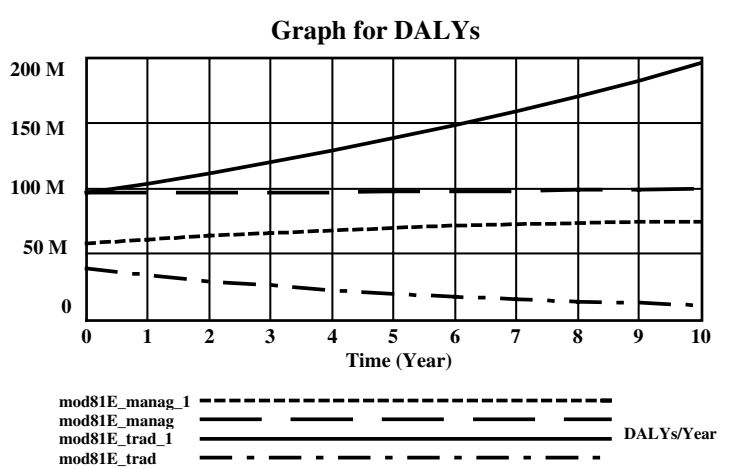

Fig. 8. Simulation of the environmental damage caused by emission of Ch VI to air of "close Moscow" 
The second approach is the management basing on the system simulation with the main objective to reach the adopted decrease of the environmental damage. The human health damage is estimated using the unit-risk concept.

The results of simulation for the model of "close Moscow" (example) are shown in Fig.8. Only in one simulated scenario (mod_81E_trad) the environmental damage decreases effectively with time.

The model includes 75 variables and factors, and the optimal values of the variables with initial values and constant factors for the system management may be obtained by simulation.

\section{Conclusions}

The system dynamics modelling of the environment-industry systems can provide the information what is necessary for the management procedures. The modelling approach may be applied for the system of various dimensions in space and time. The simulation of scenarios supports the finding of the optimal decision.

\section{References}

1. International standard ISO 14040. Environmental Management - Life Cycle Assessment Principles and framework. ISO (1997)

2. Goedkoop, M., Spriensma, R`: The Eco-indicator 99. A Damage Oriented Method for Life Cycle Impact Assessment. PRe Consultants B.V., Amersfoort, The Netherlands, Internet version (1999)

3. Kantardgi, I., Kaliagin, V., Kharif, Ch., Purvis, M. (eds.): Management of Natural Resources. Teaching manual, Nyzhny Novgorod State Technical University, Nyzhny Novgorod (2002)

4. Ford, A. Modelling the Environment. An Introduction to system Dynamics Modelling of Environmental Systems. Island Press (1999) 